\title{
FIEBRES TERCIANAS, SEQUÍAS Y LLUVIAS TORRENCIALES EN EL ALICANTE DEL SETECIENTOS
}

\author{
EDUARDO BUENO VERGARA \\ Universidad Miguel Hernández \\ ebueno@umh.es
}

\section{Resumen}

El presente artículo tiene por objeto de estudio las epidemias de fiebres tercianas que se produjeron durante el siglo XVIII en la ciudad de Alicante, desde dos enfoques diferentes. Por un lado, se aborda la relación existente entre condiciones atmosféricas y la aparición de la enfermedad, planteando que un incremento previo de la pluviosidad pudo favorecer la mayor extensión de los brotes palúdicos durante el verano. Por otro lado, realizamos una aproximación a las políticas municipales desarrolladas tanto para prevenir los contagios como para, una vez ya habían aparecido, minimizar su impacto.

Palabras clave: Edad Moderna, Alicante, Malaria, Clima, Sequía, Precipitaciones atmosféricas

\begin{abstract}
Tertian fevers, droughts and torrent rain in Alicante during the eighteenth century

The aim of this paper is to study the outbreaks of tertian fever occurred during the eighteenth century in the city of Alicante. We use two different approaches. On the one hand, we focus on the relationship between atmospheric conditions and outbreak of the disease; we conclude that a previous increase in rainfall could favored a greater extension of the malaria during the summer. On the other hand, we analyze the policies taken by the council in order to prevent the contagion and to minimise their impact if the outbreak had already begun.
\end{abstract}

Keywords: Modern Age, Alicante, Malaria, Climate, Drought, Rainfall 


\section{Introducción}

El presente trabajo tiene dos objetivos fundamentales, por un lado, incluir el elemento climático al conjunto de factores que podían determinar la aparición de las fiebres tercianas en las sociedades del Antiguo Régimen; por otro lado, entender de qué manera las poblaciones de aquella época dieron respuesta a la aparición de la enfermedad, desde el ámbito de la administración municipal. Para ello, geográficamente centramos nuestro estudio en la ciudad de Alicante y su término general, abarcando un período cronológico concreto, el siglo XVIII. De este modo, en primer lugar, realizaremos un breve recorrido por las condiciones atmosféricas generales; a continuación, nos detendremos en la relación que se puede apreciar entre estas y la irrupción de las tercianas; por último, abordamos las políticas locales que fueron desarrolladas, tanto para prevenir la aparición de la enfermedad, como para minimizar los efectos una vez había prendido el contagio.

El término «fiebres tercianas», empleado durante la época que estudiamos, era el diagnóstico de una enfermedad que, desde la medicina actual, llamamos paludismo o malaria. Esta enfermedad es causada por parásitos del género Plasmodium que se transmiten al ser humano por la picadura de mosquitos Anopheles infectados. La asimilación de una dolencia identificada en el pasado, desde otro paradigma médico, con una patología actual supone una serie de riesgos, ya planteados por otros historiadores ${ }^{1}$. En nuestro caso concreto de estudio se podrían plantear varias cuestiones: si todos los contagios documentados fueron realmente malaria, o si esta fue producida por el mismo Plasmodium, teniendo en cuenta la variedad de calificativos que solían acompañar al diagnóstico de fiebres tercianas en aquella época (contagiosas, espurias, anómalas, confusas, ambiguas, etc.). Es por ello que, huyendo de lo que puede convertirse en un debate estéril y, observando que todas las epidemias -con una excepción que será mencionada- muestran un patrón similar, hemos empleado los términos «tercianas», «malaria»y «paludismo» de manera indistinta.

La elección de las fiebres tercianas como objeto de estudio viene dada por la significativa presencia que este mal tuvo en las sociedades mediterráneas

1. Arrizabalaga, 11/3 (1993): 23-47.

Revista de Historia Moderna, n. ${ }^{o} 35$ (2017) (pp. 377-409) | ISSN-e: 1989-9823 | ISSN: 0212-5862 
en época preindustrial ${ }^{2}$. Además, durante el siglo XVIII, al tiempo que fueron remitiendo los brotes pestíferos, la malaria se fue configurando como uno de los principales problemas sanitarios, formando parte de la amplia categoría de «fiebres» que, según algunos investigadores, adquirieron un marcado protagonismo en el siglo de las Luces ${ }^{3}$, tal y como reflejan los numerosos estudios que se han ocupado del mal palúdico durante el Setecientos ${ }^{4}$. En el caso concreto de Alicante, la problemática que planteaba la llegada de las fiebres ya fue objeto de una aproximación por parte de Armando Alberola, de cuyo trabajo hemos partido a la hora para elaborar el presente artículo 5 .

Un viejo proverbio rezaba así "por tercianas no doblan campanas» ${ }^{6}$, por lo que cabe recordar que las tercianas no solían presentar una excesiva mortalidad y, por tanto, desde el punto de vista de sus repercusiones demográficas no se puede equiparar a males como la peste o, como lo fueron posteriormente, la fiebre amarilla, el cólera o algún episodio concreto de gripe. Sin embargo, no hay que olvidar que sí eran altamente incapacitantes, un hecho de especial relevancia dado que podían sumir a un jornalero en la pobreza ${ }^{7}$, teniendo en cuenta la fragilidad de las sociedades modernas ${ }^{8}$. Además, este factor de carácter social ya fue señalado por los propios contemporáneos, quienes aseguraban que lo pobladores más humildes tenían mayor propensión a enfermar y a sobrellevar peor la dolencia.

2. BRAUDEL, 2010: 341-343.

3. Peset Reig y Peset Reig, 4 (1978): 7-28.

4. Peset Reig y Peset Reig, 121 (1972): 277-375. 1972. Pérez Moreda, 1980: 336-360. Contreras MAS, 37 (1980): 83-90. PÉREZ MOREDA, 34 (1982): 295-316. 30/728 (1986): 51-64. Mateu TORTOSA, 1987: 77-104. PÉrez Medina, 6/11-12 (1991): 137-150. DíAZ PinTAdo, 21 (1991): 213-247, GARCía RuIPÉREZ y SÁNCHEZ GonZÁLEZ, 43/1 (1991): 267299. Alberola Romá, 1999: 236-273. SÁEZ GÓMEZ y MARSET CAMPOS, 52/1 (2000): 167184. Olmos TAMARit, 16 (2001). SOBREVÍA ClaVERA, 55/2 (2004): 169-196. GimÉNEZ FONT, 46 (2008): 141-157. BuENO MARÍ y JiMÉNEZ PEYDRÓ, 70/236 (2010): 678-708, Alberola Romá y Pradells Nadal, 2012: 65-93.

5. Alberola Romá, 5 (1985): 127-140. Alberola Romá y Bernabé Gil, 17 (1999): 95-112.

6. Alberola Romá, 2009: 39-67:55. Podemos encontrar referencia a ese refrán en CiBAT, 1806.

7. El tema del pauperismo en la Edad Moderna y sus implicaciones ha sido ampliamente abordado por la historiografía, ver CALLAHAN, 146 (1978): 65-71. SOUBEYROUX, 12-13 (1980): 7-227; 20-21 (1982): 7-225. CARASA SOTO, 7 (1987a): 131-150. 1987b. MAZA ZORRILLA, 1987.

8. FRANCO RUBIO, 2009: 209-251. 


\section{La relación enfermedad y clima}

\section{La visión de los contemporáneos}

La vinculación de las enfermedades con el clima propio de un lugar es una constante que hallamos desde la tradición clásica, cuyos conocimientos médicos mantuvieron su vigencia, casi inalterados, en la Europa cristiana medieval y moderna. Especialmente, desde finales del siglo XVII, no fueron pocos los galenos que se encargaron de señalar la relación entre condiciones atmosféricas y de salud, como parte de las observaciones científicas que se estaban llevando a cabo en aquella centuria, tal y como ha puesto de manifiesto Horacio Capel ${ }^{9}$. Así, fruto del espíritu utilitarista y el conocimiento aplicado, y gracias al perfeccionamiento de los instrumentos que permitían observar y medir los fenómenos atmosféricos, sin olvidar el marco de construcción estatal impulsado por los Borbones y la fundación de instituciones científicas, encontramos la obra de Francisco Fernández de Navarrete, Ephemérides Baromético-Médicas ${ }^{10}$, publicada a partir de 1737 bajo el amparo de la Academia Matritense, donde eran recogidas numerosas informaciones climáticas de diferentes partes del Reino, enviadas por corresponsales, con el objetivo de contribuir a mejorar el conocimiento sobre las enfermedades que aquejaban y diezmaban periódicamente a la población. Aunque la muerte de Fernández Navarrete en 1742 privó de continuidad al proyecto, las observaciones continuaron llevándose a cabo por médicos que participaban de esa idea de conexión entre las condiciones meteorológicas y las causas de las enfermedades como Gaspar Casal, Andrés Piquer o Jacinto Nieto de Piña ${ }^{11}$. En la década de los ochenta comenzó a publicarse el Memorial Literario ${ }^{12}$, un periódico que incluía entre sus páginas la divulgación de las novedades

9. CAPEL SÁEZ, 32-33 (1998): 79-105.

10. El título completo es Ephemérides Barométrico-Médicas Matritenses para el más puntual, y exacto cálculo de las Observaciones que han de iluminar la Historia natural, y Médica de España: extractadas de orden de la Real Academia Médica Matritense por el Doctor Francisco Fernández Navarrete, Cathedrático de Medicina de la Imperial Universidad de Granada, Médico de Cámara con exercicio de su Magestad, y Académico de Número de dicha Real Academia.

11. CAPEL SÁEZ, 32-33 (1998): 79-105.

12. URZAinqui Miqueleiz, 52-53 (1990): 501-516, LARriba, 5 (2008). 16 (2010): 1-88. Alberola RomÁ, 12 (2015). 
científicas y técnicas que no solían ser tratadas en otra prensa de la época. En el marco de esta temática se inscribió el Diario Meteorológico, cuyo planteamiento era el mismo que el auspiciado en la década de los treinta por la Academia Matritense, a fin de desterrar la ciencia de la astrología y conocer de qué modo el medio ambiente condiciona la aparición de las enfermedades, amén de otras circunstancias como la fertilidad de la tierra o los rendimientos de las cosechas ${ }^{13}$.

En el propio Memorial Literario, el médico Manuel Troncoso relacionaba las fiebres padecidas en Córdoba en 1785 con las «copiosas lluvias, inundaciones considerables y vientos impetuosos». El también médico Antonio Ased Latorre en su Memoria instructiva de los medios de precaver las malas resultas de un temporal excesivamente húmedo señalaba que «es constante que toda la superficie de la tierra está llena de agua en tiempos de lluvias, y que se forman varios estanques de ella en diferentes parajes; también es cierto que se mezcla con varios cuerpos tanto vegetales como minerales y animales, y con el calor del centro de la tierra y el de la Atmósfera, se corrompen ${ }^{14}$. Por su parte, Joseph Masdevall apuntaba que una primavera lluviosa y un verano caluroso contribuían a la aparición de las calenturas ${ }^{15}$. Aunque siempre teniendo en cuenta, en estos escritos, que no eran las lluvias en sí, sino que era la presencia de aguas estancadas y pantanosas las que podían «corromperse», dentro -por supuesto- de las interpretaciones de las enfermedades propias de la ciencia médica de la época ${ }^{16}$.

\section{Relación enfermedad y clima en la actualidad}

En la actualidad, la influencia del clima sobre la aparición y el desarrollo de las enfermedades es un tema que ha dado pie a interesantes estudios, especialmente desde planteamientos que ponen el foco en el cambio climático y el calentamiento global ${ }^{17}$. Estos trabajos también insisten en que la vinculación

13. Alberola Romá, 12 (2015).

14. Ased Latorre, 1784?: 14-15. Alberola Romá, 12 (2015).

15. MASDEVALL, 1797: 53-54.

16. Cipolla, 1993. Urteaga, 29 (1980); 5-6 (1985): 417-425. Carreras Panchón, 1991.

17. GitheKo, LindSAY, CONFALONIERI y PATZ, 78/9 (2000): 1136-1147. ReITER, 109/ Supplement 1 (2001): 141-161. ZHOU, MinAKAWA, GITHEKO y YAN, 101/8 (2004): 2375-2380. LÓPEZ VÉlez y MOLina MORENo, 79/2 (2005): 177-190. MCMiCHAEL, 
entre condiciones atmosféricas y enfermedad no presenta, en absoluto, un desarrollo lineal y establecido. Y es que existen muchas variables que van a determinar la aparición del paludismo, como la temperatura experimentada (y sus cambios, a veces, bruscos), el tipo de vector, que no responde del mismo modo a las condiciones ambientales, la humedad del aire, la existencia de aguas detenidas, la presencia de infraestructuras sanitarias, el número de habitantes o su distancia con el presunto foco de la enfermedad. Así, por ejemplo, un aumento moderado de temperatura favorece la proliferación del vector y el agente patógeno que, sin embargo, puede ser neutralizado si el incremento es muy fuerte. Todos los estudios señalan que las condiciones sociales y los recursos preventivos y de control son fundamentales para evitar los casos de paludismo y la gravedad de los mismos. De modo que, en unas sociedades como las de la Edad Moderna, en la que el conocimiento sobre la etiología de la enfermedad y las actuaciones políticas eran mucho menores, la influencia de las condiciones atmosféricas fue fundamental para el desarrollo de las tercianas.

\section{Clima en Alicante durante el siglo XVIII}

Antes de entrar de lleno en la relación que pudo existir entre las condiciones atmosféricas y la aparición de las tercianas, es necesario realizar una breve aproximación al clima imperante en el siglo XVIII alicantino ${ }^{18}$. Para ello hemos empleado las rogativas pro pluvia a fin de localizar los periodos más secos de la centuria. Mediante la localización, identificación y cuantificación de estas ceremonias religiosas comunitarias, propias de las sociedades rurales, es posible saber cuándo se produjeron las sequías. Se trata de una metodología para conocer el clima pretérito que ha alcanzado cierto desarrollo en los últimos

WoOdrufF y Hales, 367/9513 (2006): 859-869. Bueno Marí y JimÉnez Peydró, 24/4 (2010): 347-353. ARCOS GONZÁLEZ y ESCOLANO ESCOBAR, 23/5 (2011): 386-393. ROGERS y RANDOLPH, 289/5485 (2014): 1763-1766.

18. La línea de investigación en Historia y Clima que se ha desarrollado tanto dentro como fuera de nuestras fronteras se ha mostrado muy fecunda en las últimas décadas, y una buena muestra de ello es el presente número de Revista de Historia Moderna. Anales de la Universidad de Alicante o la reciente publicación del libro colectivo ARRIOJA DíAZ Viruell y AlBEROla RomÁ, 2016. Una puesta al día de los avances realizados desde este abordaje en AlBEROLA RomÁ, 2014; 2016: 739-759. 
años, dando lugar a un creciente número de estudios ${ }^{19}$. A través del acopio, ordenación y cuantificación de estas ceremonias, hemos podido realizar un acercamiento a los periodos más secos que se experimentaron en la ciudad durante el Setecientos ${ }^{20}$. Esta información será completada con informaciones que hacen referencia a los destrozos provocados por las lluvias gracias a las cuales es posible tener constancia de la presencia de precipitaciones.

De manera sintética, encontramos dos periodos bien diferenciados en el siglo $^{21}$. El primero de ellos abarcaría desde el comienzo de la centuria hasta finales de la década de los sesenta y estuvo caracterizado por la presencia de ciclos cortos de sequía. El otro periodo, desde los sesenta hasta finales del siglo, en el que la escasez hídrica se dejó sentir con gran intensidad, pero coincidiendo en el tiempo con la presencia de importantes lluvias torrenciales. Esta situación fue generalizada en el mediterráneo occidental y ha sido denominada como anomalía climática Maldá22.

Dentro del primer periodo, los años centrales de la década de los veinte fueron los más difíciles, organizándose numerosos oficios para suplicar lluvias. En el lado opuesto, en los años cuarenta, por lo general, no se experimentó falta de precipitaciones, a excepción de los años $1742^{23}$ y $1749^{24}$, en los cuales se realizaron rogativas, aunque las lluvias no tardaron en aparecer colmando las necesidad hídricas a juicio de los regidores del ayuntamiento ${ }^{25}$. En el propio año 42, después de la sequía, las lluvias arreciaron y perfilaron una primavera y un verano muy inestables. En ese sentido, el testimonio del

19. MARTín VIDE y BARRIENDOS VALLVÉ, 30/2 (1995): 201-221. BARRIENDOS VALLVÉ, 30-31 (1996): 69-96. ROMERO MARTÍN y MÁYER SUÁREZ, 2002: 533-542. ZAMORA PASTOR, 2002. Fernández Cortizo, 17 (2005): 259-298. CuAdrat Prats, 29-30 (2012): 177-187. Bueno Vergara, 2014: 19-75. Alberola Romá, Bueno Vergara y García TORRES, 2016: 123-155.

20. Una exposición pormenorizada de la metodología empleada en BUENO VERGARA, 2014: 32-39.

21. Para más detalles sobre la caracterización climática dieciochesca ver BUENO VERGARA, 2014: 40-75. Alberola Romá, Bueno Vergara y García TORRES, 2016: 123-155.

22. BARRIENDOS VALLVÉ y LLASAT, 2009: 253-286.

23. Archivo Municipal de Alicante (en adelante AMA), Arm. 9, lib. 32, ff. 91-91v.

24. AMA, Arm. 9, lib. 39, f. 6.

25. Tras las precipitaciones que sucedieron a las rogativas de 1742 se celebró una misa en acción de gracias, AMA, Arm. 9, lib. 32, ff. 107-107v. Para el caso de 1749, AMA, Arm. 9, lib. 39, ff. 49-49v. 
prior del hospital de la ciudad, el de San Juan de Dios, señalaba en el mes de mayo la cantidad de enfermos que se estaban atendiendo en medio de la «intemperie de la estación actual $»^{26} y$, ya en el verano, la crecida en el río Montnegre, el río rambla que atraviesa la huerta de la ciudad, puso en alerta a todos los vecinos por el temor a su desbordamiento ${ }^{27}$.

En cuanto al segundo período, también podemos distinguir diferentes fases. Desde aproximadamente 1760 hasta 1782 observamos la fase más seca y es significativo que entre 1768 y 1783 se produjeron rogativas todos los años en mayor o menor grado, en especial durante la primera mitad de los 70 . Entre 1783 y 1787 se produjo un breve paréntesis en el panorama marcado por la sequía. Pese a que a principios de 1783 se celebraron rogativas pro pluvia, en los meses siguientes el tiempo atmosférico cambió drásticamente y la abundancia de lluvias hizo temer por las cosechas del año siguiente, llegándose a celebrar rogativas para que amainase el temporal ${ }^{28}$. Además, en ese mismo año se produjo la erupción del volcán Laki en Islandia, lo que provocó enormes trastornos climáticos en toda Europa ${ }^{29}$. En los años siguientes, las lluvias continuaron siendo habituales, aunque las secas volvieron a ser la tónica general a partir de 1787, en una situación que se prolongó hasta 1792. Al igual que ocurrió en 1783, la pertinaz sequía dejó paso a las lluvias torrenciales caídas en septiembre de 1793, causantes de numerosos desperfectos en la ciudad y, sobre todo, en los cultivos de la huerta. Desde ese momento hasta final de siglo, no hubo necesidad de agua a juzgar por la ausencia de rogativas pro pluvia.

\section{La presencia de las fiebres tercianas}

El paludismo fue un incómodo visitante que cada verano, en mayor o menor medida, afectaba a los habitantes de las sociedades modernas. En las actas del cabildo alicantino, se han registrado noticias que daban cuenta de la

26. AMA, Arm. 9, lib. 32, f. 128.

27. AMA, Arm. 9, lib. 32, ff. 212-213.

28. AMA, Arm. 9, lib. 78, ff. 274v y 283v-284.

29. Alberola Romá, 2012: 325-346. ThORdason y SElF, 108/D1 (2003): 1-29. Witham y OpPENHEIMER, 67/1 (2004): 15-26. SCHMidT, OSTRO, CARSLAW, Wilson, THORDARSON, MANN y SIMMONS, 108/38 (2011): 15710-5. GARNIER, 195/4-5 (2011): 1043-53. 
presencia de esta enfermedad, haciendo referencia a casos puntuales, pero que no despertaron la alerta de los poderes municipales. Por ejemplo, en agosto de 1760, los vecinos de la calle Mayor del arrabal de San Antón elevaban un memorial al cabildo en el que informaban de los casos de tercianas que estaban padeciendo ${ }^{30}$, o en 1772 , cuando el médico titular, Carlos Tomás Ximeno, solicitaba permiso para acompañar a su mujer, aquejada de tercianas, a Monforte, donde pudiese recuperar la salud ${ }^{31}$. En ocasiones, se pedía algún tipo de socorro económico al ayuntamiento, o los propios vecinos informaban de la existencia de algún foco de insalubridad que podía desencadenar la epidemia, principalmente las aguas estancadas. Así, incluso en los años en los que las tercianas no tuvieron gran incidencia, el vecindario experimentó cierto número de casos que no requirieron la aplicación de acciones fuera de lo normal, sino que la población estuvo razonablemente atendida por las instancias asistenciales tradicionales. Desde luego que, esta situación que estudiamos en el caso alicantino, puede extrapolarse a, prácticamente, todo el mundo mediterráneo.

Sin embargo, en determinadas circunstancias, la enfermedad superaba los límites que podríamos considerar como «normales», prendiendo el contagio entre la población y obligando a articular una serie de respuestas y movilizar recursos encaminados a minimizar los daños. Así, en el siguiente apartado, realizamos un breve repaso por esos episodios extraordinarios que se dieron en la ciudad y que quedan resumidos en la Tabla 1. No nos detendremos en el desarrollo fáctico de los acontecimientos que se produjeron durante esos contagios, cuya evolución ha sido abordada convenientemente en otros trabajos $^{32}$. Prestaremos atención, en cambio, al contexto climático que acompañó esos episodios palúdicos y a las medidas emprendidas para prevenir el contagio y aquellas otras desarrolladas cuando ya había prendido y se intentaba minimizar los daños.

30. AMA, Arm. 9, lib. 50, ff. 106-106v.

31. AMA, Arm. 9, lib. 66, ff. 239-239v.

32. Alberola Romá, 5 (1985): 127-140. Alberola Romá y Bernabé Gil, 17 (1999): 95-112. BUENO VERGARA, 2014. 
Tabla 1. Resumen de los años en los que se produjeron brotes de fiebres tercianas, enfermos registrados, muertos y población existente en la ciudad de Alicante durante el siglo XVIII

\begin{tabular}{|c|c|c|c|}
\hline Año & Enfermos & Muertos & $\begin{array}{c}\text { Población en } \\
\text { habitantes }\end{array}$ \\
\hline 1733 & - & - & $\begin{array}{c}12.604 \\
(\text { en } 1735)\end{array}$ \\
\hline 1746 & $\begin{array}{l}\text { Más de } 200 \text { solo en Babel y San } \\
\text { Francisco }\end{array}$ & $\begin{array}{l}56 \text { (solo en agosto y } \\
\text { septiembre) }\end{array}$ & - \\
\hline 1753 & 219 & - & $\begin{array}{c}14.987 \\
(\text { en } 1754)\end{array}$ \\
\hline 1766 & $\begin{array}{l}295 \text { en la parroquia de San } \\
\text { Nicolás y «un número muy alto» } \\
\text { en la parroquia de Santa María }\end{array}$ & - & - \\
\hline 1767 & - & - & - \\
\hline 1768 & $606-640$ & - & - \\
\hline 1777 & En torno a 600 & - & - \\
\hline 1786 & $\begin{array}{l}530 \text { en la ciudad } \\
784 \text { en el corregimiento }\end{array}$ & $\begin{array}{l}26 \text { en la ciudad } \\
35 \text { en el corregimiento }\end{array}$ & 18.212 \\
\hline 1794 & - & - & 20.729 \\
\hline
\end{tabular}

Fuentes: Las cifras de población las hemos obtenido de GIMÉNEZ LÓPEZ, 1981: 36-73. Las cifras sobre las muertes y defunciones proceden de AMA, Actas del cabildo, armario

9, libros 23, 36, 43, 56, 58, 59, 60, 72 y 89 y Arm. 15, lib. 15. Elaboración propia.

\section{Relación entre clima y fiebres tercianas}

A la hora de intentar establecer una unión entre el tiempo atmosférico y la aparición de las tercianas, es necesario advertir que es imposible establecer una relación causal inmediata entre aumento o reducción de las precipitaciones y repunte o ausencia de malaria. Tampoco en los estudios llevados a cabo en la actualidad, a los que hemos hecho referencia anteriormente, en los que es posible evaluar, por motivos obvios, más variables (pluviosidad, humedad, temperatura, horas de sol, migraciones, desarrollo de inmunidad) se puede establecer, hasta la fecha, una relación causa-consecuencia.

Hecha esta anotación, sí se puede establecer un escenario ideal para que se produzca la extensión de la malaria. Este sería un otoño o una primavera 
con abundancia de lluvias y un verano de temperaturas elevadas. El desarrollo del vector se realiza en aguas detenidas que pueden encontrase en numerosos lugares, desde las huellas dejadas en tierra por la caballería, hasta las lagunas de grandes dimensiones, pasando por los campos de arroz, balsas de riego, etc. Por este motivo, son las precipitaciones las que, sumadas a la configuración geográfica de la ciudad, propiciaban un entorno ideal para la proliferación del vector $y$, por tanto, aumentaba la probabilidad de que se extendiesen las tercianas.

De este modo, reconstruyendo las condiciones atmosféricas, podremos contribuir a comprender en su complejidad el funcionamiento de las comunidades pasadas, añadiendo otro enfoque más como es el riesgo por la aparición de brotes de paludismo y los mecanismos para hacerle frente. Al hilo de esta idea, en un estudio también centrado en el siglo XVIII, principalmente en el antiguo Reino de Valencia, Pablo Giménez ha señalado la importancia del uso del suelo, vinculando la presencia de fiebres no solo a la climatología, sino también a la extensión de los arrozales ${ }^{33}$.

Podemos señalar que, en general, los contagios experimentados en la ciudad (1733, 1746, 1753, 1766, 1767, 1768, 1777, 1786 y 1794) coincidieron con periodos en los que no se llevaron a cabo rogativas pro pluvia y, por tanto, no hay indicadores de sequía. Al mismo tiempo, en los años en los que se padeció una gran escasez hídrica, no se han documentado casos de paludismo relevantes, salvo en dos ocasiones (1753 y 1786) que serán comentadas más adelante. Esta información climática puede ser completada con las noticias que hacen referencia a episodios de lluvias de alta intensidad horaria, a través de la constatación de diferentes daños que las trombas de agua provocaron. De este modo, podemos contextualizar con mayor detalle el temple atmosférico que preludió la aparición de los episodios de malaria más importantes de Alicante durante el siglo XVIII y que analizamos a continuación.

El brote epidémico acontecido en 1733 es el que menor huella documental ha dejado. Tampoco hemos podido localizar gran cantidad de información climática con la que contextualizarlo. No obstante, se puede hacer referencia

33. GIMÉNEZ FONT, 46 (2008): 141-157.

Revista de Historia Moderna, n. 35 (2017) (pp. 377-409) | ISSN-e: 1989-9823 | ISSN: 0212-5862 
a la necesidad, comunicada en el cabildo en agosto de 1732, de reparar uno de los azudes construidos en el río Montnegre que, con anterioridad, había sido dañado por el ímpetu de las avenidas ${ }^{34}$.

El contagio de 1746 se sitúa en uno de los periodos caracterizados por la abundancia de agua. El brote de «tercianas perniciosas», según lo definieron los propios regidores del ayuntamiento, se achacó a la presencia de aguas estancadas existentes al sur del núcleo urbano ${ }^{35}$. En julio del año anterior, se comunicaba en el cabildo cómo se estaba echando a perder el grano guardado en uno de los almacenes que poseía la ciudad, debido a las lluvias que entraban en el interior por culpa del mal estado de la construcción ${ }^{36}$.

En cuanto al episodio tercianario de 1753, encontramos numerosas referencias de importantes lluvias previas a la aparición. El clero de la colegial de San Nicolás identificó la enfermedad como «calenturas tercianas contagiosas» ${ }^{37}$, mientras que los médicos la definieron como «calenturas anómalas, confusas, ambiguas o espurias». Los galenos señalaron que «tratadas en los principios con suavidad y paciencia y dieta médica, terminan en salud como lo hacen todas las fiebres tercianarias ${ }^{38}$. A lo largo de 1752 las lluvias provocaron numerosos daños en los caminos de entrada y salida de la ciudad ${ }^{39}$, en las acequias, que se vieron quebradas y colmadas de escombros de arrastrado $^{40}$, en la fábrica del monasterio de Santa Faz, sobre el que el cabildo ejercía su patronato $^{41}$, en edificios públicos y también particulares ${ }^{42}$, y en el puerto ${ }^{43}$. La abundancia de agua en la partida de la Almaxá preocupó a los regidores, ya desde los primeros meses de 1752 , por las repercusiones sanitarias que pudiese acarrear ${ }^{44}$. A comienzos de 1753 se mantuvieron las precipitaciones

\footnotetext{
34. AMA, Arm. 9, lib. 22, f. 96.

35. AMA, Arm. 9, lib. 36, ff. 100-101.

36. AMA, Arm. 9, lib. 35, f. 87.

37. AMA, Arm. 9, lib. 43, ff. 124v-125.

38. AMA, Arm. 9, lib. 43, ff. 127-127v.

39. AMA, Arm. 9, lib. 42, ff. 3v-4v.

40. AMA, Arm. 9, lib. 42, ff. 196-196v.

41. AMA, Arm. 9, lib. 42, ff. 200-201.

42. AMA, Arm. 9, lib. 42, f. 215.

43. AMA, Arm. 9, lib. 42, ff. 220-221.

44. AMA, Arm. 9, lib. 42, ff. 9v-10.
} 
dos meses antes de que se celebrasen las rogativas a las que ya hemos hecho referencia ${ }^{45}$.

Entre 1766 y 1768 se encadenaron tres años en los que se dieron episodios tercianarios, un hecho insólito hasta ese momento en el siglo XVIII. No hay que descartar, en cualquier caso, que la malaria llegara acompañada de otras enfermedades diferentes, sobre todo en 1768, cuando el contagio se prolongó durante el invierno, algo poco habitual para tratarse de tercianas. El contagio de 1766 se concentró principalmente en el barrio de San Francisco, al sur de la ciudad. Los propios vecinos de este barrio, en una carta remitida al cabildo, señalaban que las fiebres estaban causadas por el mal estado de las calles, convertidas en lodazales a causa de las recientes lluvias ${ }^{46}$. En los últimos compases de 1765, especialmente durante el mes de noviembre, a resultas de los aguaceros ocurridos, se repetían los daños que habitualmente seguían a un temporal, haciendo necesaria la limpieza de las calles ${ }^{47}$.

En 1767 fue el arrabal de San Antón el más afectado por el paludismo. En esta ocasión no se achacó tanto el origen de la enfermedad a las aguas estancadas y «corrompidas», sino a una serie de problemas de salubridad en el marco del paradigma miasmático de la época, como lo eran los malos olores procedentes del Hospital Militar y los vertidos de sus letrinas, el cieno formado alrededor de la fuente que abastecía de agua, los desperdicios de las tenerías y exhalaciones de la fábrica de almidón, la presencia de estercoleros cercanos a las viviendas o la sangría practicada a los animales en plena calle ${ }^{48}$. Siendo este arrabal el núcleo de población que mayor crecimiento experimentó durante el Setecientos, no es de extrañar que en ese enclave se dieran las condiciones higiénicas más difíciles, a lo que habría que sumar la cercanía con el barranco de Canicia (actualmente integrado en la ciudad) donde también se acumulaban las aguas en charcas y pozas. En cuanto al clima, las lluvias fueron copiosas durante el otoño de $1766^{49}$ y también en los primeros momentos de la primavera del año siguiente, meses antes del contagio.

45. AMA, Arm. 9, lib. 43, f. 27v.

46. AMA, Arm. 9, lib. 56, ff. 225v-256.

47. AMA, Arm. 9, lib. 55, ff. 193, 197-197v; lib. 56, ff. 85v-86.

48. AMA, Arm. 9, lib. 58, ff. 240-24lv.

49. AMA, Arm. 9, lib. 56, ff. 255v-256, 275-276, 294-294v, 296. 
El brote de 1768, que suscitó gran preocupación entre las autoridades municipales, se produjo durante el invierno, lo cual puede plantear dudas sobre su identificación como malaria ${ }^{50}$. En cualquier caso, vino precedido de fuertes aguaceros en octubre de 1767 que provocaron daños en la fábrica del Hospital Militar y en uno de los almacenes de la ciudad, además de dejar enlodadas e intransitables algunas calles ${ }^{51}$.

En 1777 encontramos nuevamente un contagio precedido por las fuertes precipitaciones sobrevenidas. Así, en octubre de 1776 se registraron los daños materiales ya habituales como eran la ruina en edificios o la caída de desprendimientos desde el monte Benacantil, en cuya ladera se hallaba el centro urbano, al margen, por supuesto, del enlodado en las vías ${ }^{52}$. A finales de ese mismo año, el fontanero de la ciudad, encargado de reparar acequias y tuberías tras las intensas lluvias, informaba al ayuntamiento de las obras que venía realizando a causa de los tres meses de incesantes precipitaciones que habían tenido lugar a principios de $1777^{53}$. Durante el mes de junio de ese año prendió el contagio, con gran afectación en los barrios de San Francisco y Raval Roig, este último de tamaño reducido al norte de la ciudad. En ambos enclaves se habían documentado la presencia de aguas estancadas, del mismo modo que se hizo en San Antón, donde el prior de los capuchinos señalaba al cabildo que, tras consultar con un médico, habían comprendido que el origen de las fiebres radicaba en los «vapores fétidos que exhalaban continuamente las aguas corrompidas inmediatas al convento $»^{54}$.

El episodio de 1786 estuvo enmarcado dentro del lluvioso paréntesis al que hemos hecho referencia con anterioridad y que comenzó en 1783. Además de las coordenadas climáticas, este brote estuvo acompañado de una inusitada extensión de la enfermedad por gran parte de la geografía peninsu$\operatorname{lar}^{55}$. Las lluvias cayeron de manera abundante tanto a finales de 1785, como a

50. Perdiguero Gil y Bernabeu Mestre, 11 (1995): 165-176. Perdiguero Gil, 22 (2002): 121-150.

51. AMA, Arm. 9, lib. 58, ff. 305v, 308; lib. 59, ff. 209-209v.

52. AMA, Arm. 9, lib. 71, ff. 277v-278, 280-282.

53. AMA, Arm. 9, lib. 71, ff. 310v-311.

54. AMA, Sanidad, caj. 11, carp. 22.

55. PÉREZ MOREDA, 1980. 34 (1982): 295-316. 
principios de $1786^{56}$, después de las cuales se celebró una rogativa pro pluvia secreta, lo que revela la intensidad leve de la necesidad de agua.

El brote acaecido en 1794 fue el último experimentado en la centuria y se produjo, especialmente, en la partida de El Campello, al norte de la ciudad, aunque también en el barrio de San Francisco, donde los religiosos que habitaban el convento allí situado, informaban al cabildo que habían caído todos enfermos, de modo que se habían visto obligados a abandonar su casa para ser atendidos por los vecinos del barrio ${ }^{57}$. En una consulta realizada a un médico que, habitualmente atendía a la población de esa zona, este sostenía que la causa de la epidemia era una gran porción de agua detenida en un paraje cercano. Otro facultativo, esta vez titular y enviado en comisión para reconocer el estado sanitario del lugar, confirmó la existencia de agua estancada que resultaba «nociva a la salud pública a causa que, fermentada por el sol, ha contraído putrefacción, infectando y malificionando el ambiente ${ }^{58}$.

Disponemos de gran cantidad de información climática previa a este episodio debido a la inusitada intensidad con la que aparecieron las lluvias. Fueron abundantes y en la primavera de 1793 ya se temía un brote durante el otoño por el estancamiento de aguas y su «corrupción ${ }^{59}$. Sin embargo, fue en septiembre, la noche del 7 al 8, cuando cayó mayor cantidad de agua, del mismo modo que sucedió en otros lugares del País Valenciano ${ }^{60}$. La abundancia de las aguas elevó el caudal del Montnegre que salvó la pared del pantano de Tibi, provocando una avenida que inundó parte de la huerta de la ciudad, malogrando la cosecha de uva de ese año y del siguiente ${ }^{61}$. Además, provocó otra serie de daños de diferente consideración en los molinos situados en los márgenes del río, con la consiguiente carestía de harina ${ }^{62}$, en los azudes de Sant Joan y Mutxamel que dividían el agua para regar las distintas partidas de la huerta, dejándolos inservibles y cuya reparación no llegó hasta años

\footnotetext{
56. AMA, Arm. 9, lib. 80, ff. 60-63v, 181-181v, 284-285v; lib. 81, f. 45.

57. AMA, Arm. 9, lib. 89, ff. 186v.

58. AMA, Arm. 9, lib. 89, ff. 198-200.

59. AMA, Arm. 9, lib. 88, ff. 125v-126.

60. Alberola Romá, 2010: 205-219.

61. BUENO VERGARA, 2013: 55-79.

62. AMA, Arm. 9, lib. 88, f. 184v.
} 
más tarde ${ }^{63}$. Las monjas clarisas de Santa Faz exponían cómo una «inaudita avenida» había provocado un «naufragio» en su monasterio, echando a perder todo el aceite, pan, harina y demás alimentos de los que disponían, así como todas sus posesiones materiales ${ }^{64}$. Aunque con menor intensidad, las lluvias se repitieron en noviembre, provocando derrumbes desde el Benacantil, enlodando calles y causando daños en edificios ${ }^{65}$. En el mes de marzo de 1794, cuando ya despuntaba la primavera, el cabildo mostró su preocupación habida cuenta de las lagunas de agua detenida que habían proliferado por todo el término ya que constituían un riesgo muy serio para la salud pública, una sospecha que, finalmente, se vio confirmada.

\section{Acción municipal contra las fiebres tercianas}

En este tercer apartado nos ocuparemos de las medidas que fueron tomadas desde los poderes municipales para hacer frente a las tercianas. Como es evidente, estas políticas no estaban encaminadas a frenar exclusivamente el paludismo, sino también las demás dolencias. Pero el hecho de que las tercianas fueran, en cierta manera, esperadas cada verano, hace que las acciones adoptadas tuvieran como objeto primordial minimizar su impacto. Así, teniendo en cuenta las providencias desarrolladas por el cabildo alicantino, distinguiremos entre: las llevadas a cabo desde el punto de vista de la prevención, y las resoluciones tomadas para mitigar el daño una vez que el contagio ya había prendido entre la población.

Tanto las medidas de prevención como las de actuación durante las epidemias se caracterizaron por las múltiples dificultades que surgieron para ponerlas en práctica. Además de las limitaciones presupuestarias y técnicas, también hay que tener en cuenta que los embates periódicos de las tercianas eran afrontados con resignación y fatalismo. Por último, no podemos olvidar que, hasta bien entrado el siglo xx, los ayuntamientos -y las administraciones, en general- no tenían una vocación de servicio público, ni tampoco existía una concepción de «salud pública» equiparable a la que se desarrollará más adelante desde finales del siglo XVIII y principios del XIX.

63. Alberola RomÁ, 1999: 311-313; 1994.

64. AMA, Arm. 9, lib. 88, ff. 190v-192.

65. AMA, Arm. 9, lib. 88, ff. 196-196v, 219-219v.

Revista de Historia Moderna, n. 35 (2017) (pp. 377-409) | ISSN-e: 1989-9823 | ISSN: 0212-5862 
Durante el Antiguo Régimen la salud pública se gestionó fundamentalmente en el ámbito municipal y la ciudad de Alicante desarrolló en todo momento acciones encaminadas a evitar que la enfermedad prendiera entre la población. Por su parte, la presencia de la Monarquía en este ámbito apenas destacó, más allá de la prevención contra las grandes epidemias, sobre todo a raíz de la creación de la Junta General de Sanidad en el contexto de la peste de Marsella ${ }^{66}$, o la sanción de las disposiciones tomadas en el ámbito local.

\section{Labores de prevención}

Durante la época que estamos estudiando, el origen de las fiebres tercianas estaba perfectamente identificado, si bien es cierto que desde otro paradigma científico. En el contexto de la concepción miasmática de la enfermedad, la explicación admitida era que las aguas estancadas se «corrompían» durante la estación cálida, y emanaban una suerte de éter nocivo que, a través del aire, se extendía y, al ser inhalado, desencadenaba la enfermedad en el organismo. En la raíz etimológica de la enfermedad encontramos esta explicación, puesto que «paludismo» procede del latín «palus-paludis», es decir, pantano o charca, mientras que el vocablo «malaria» procede del italiano y remite al mal estado del aire.

Esa visión estaba plenamente interiorizada por la población y hay numerosos ejemplos de vecinos, religiosos o médicos que apuntan a las aguas encharcadas como origen de las fiebres. Por ejemplo, en julio de 1715, los religiosos del convento de San Francisco solicitaban al cabildo que se diese salida a unas aguas embalsadas que podían «perjudicar la salud» de los moradores del convento ${ }^{67}$. Pasados los años, a principios de septiembre de 1753 fueron llamados los médicos ante el cabildo para conocer la situación, asegurando que los enfermos se encontraban en mayor número en el barrio de San Francisco y Raval Roig por «la laguna inmediata al baluarte de San Carlos» y por la constitución de «aguas pantanadas» localizadas en las proximidades de ambos barrios $^{68}$. El vecindario también hizo llegar sus preocupaciones por los

66. Rodríguez OCAÑA, 7-8 (1988): 145-170. RodríGuez OCAÑA y MARTínEZ NaVARRO, 2008.

67. AMA, Arm. 9, lib. 5, f. 101.

68. AMA, Arm. 9, lib. 43, f. 127.

Revista de Historia Moderna, n. ${ }^{\circ} 35$ (2017) (pp. 377-409) | ISSN-e: 1989-9823 | ISSN: 0212-5862 
focos de contagio, como en octubre de 1766, cuando los vecinos del barrio de San Francisco elevaron una protesta por la falta de salubridad en sus calles, empeoradas por las recientes lluvias, y que consideraban era causante de las fiebres que se estaban experimentando ${ }^{69}$.

De este modo, en un clima con propensión a la aridez como el del sudeste peninsular, las lluvias eran recibidas con regocijo e, incluso, se les atribuía la cualidad de «limpiar» la atmósfera de los temidos miasmas. Sin embargo, debido a la configuración geográfica del territorio alicantino, surcado de ramblas y con amplios espacios con tendencia a acumular aguas pluviales, además de un régimen pluviométrico caracterizado por precipitaciones equinocciales de alta intensidad horaria, era habitual que en primavera y verano hubiese considerables cantidades de agua detenidas en las inmediaciones de la ciudad.

Al margen de estas causas naturales, existían otras derivadas de la acción humana que también se consideraban causantes de los brotes epidémicos. Se trataría de cuestiones surgidas dentro de la dinámica de la vida urbana y la realización de actividades productivas. En este sentido, como posible causa de enfermedad encontramos, solo por citar unas cuantas, el precario sistema de alcantarillado, el vertido de basuras y desperdicios en las calles, los estercoleros en las inmediaciones de las viviendas, los lavaderos de ropa con agua no corriente, los enterramientos intramuros, las emanaciones procedentes de las destilerías de aguardiente, los vapores de las tenerías, o las exhalaciones producidas por los ameradores de esparto o cáñamo ${ }^{70}$. Se trataba de problemas compartidos por casi la totalidad de ciudades durante la Edad Moderna ${ }^{71}$, cuya detección se realizaba a través del olor, indicativo inequívoco de la existencia de los miasmas ${ }^{72}$.

Las políticas encaminadas a evitar la aparición de las enfermedades pasaban por eliminar los focos del posible contagio. En lo que respecta a los factores naturales, la gestión de las acumulaciones de aguas fue muy dificultosa. Desde los primeros compases del siglo se llevaron a término algunas obras

69. AMA, Arm. 9, lib. 56, ff. 255v-256.

70. Para las cuestiones relacionadas con la higiene pública en la ciudad de Alicante ver BuENO VERGARA, 2014: 147-19.

71. La higiene urbana es un tema al que se le ha dedicado gran atención, entre los numerosísimos trabajos ver GUERRAND, 1991. CipOLLA, 1993.

72. Corbin, 1987. LARREA Killinger, 1997. 4/5 (2010): 24-43. 
para desecar el pantano de la cercana localidad de Monforte (perteneciente al término general de Alicante), para lo cual fue necesaria la movilización de trabajadores especializados, con el consiguiente coste económico. Sin embargo, proyectos de mayor envergadura como el saneamiento de la Albufereta, no se llevó a cabo hasta el siglo Xx, a pesar de los intentos que se produjeron con anterioridad $^{73}$. Esta laguna, situada al norte de la ciudad, era el humedal más importante de la zona, aunque ni mucho menos el único.

En los cauces de los barrancos y las tierras aledañas a estos, las aguas se detenían y formaban acumulaciones sobre las que no siempre se intervenía. Un ejemplo muy evidente lo encontramos durante el brote de 1746 cuando, a pesar de las disposiciones tomadas en julio en la reunión del cabildo tocantes a la limpieza de las balsas que se consideraban foco del contagio y que padecían los vecinos de San Francisco ${ }^{74}$, para principios de octubre aún no se había llevado a cabo esa medida ${ }^{75}$.

En cuanto a las respuestas dadas ante los problemas relacionados con la acción antrópica, el cabildo intentó en todo momento regular las actividades consideradas dañinas y alejar del núcleo urbano los focos de insalubridad. Por ejemplo, existía un servicio de recogida de basuras que el municipio concedía en arrendamiento ${ }^{76}$, había una normativa para mantener los estercoleros a no menos de 700 metros de la ciudad ${ }^{77}$, algo similar a lo decretado para los ameradores de esparto y cáñamo ${ }^{78}$, las destilerías de aguardiente también se sacaron fuera de las murallas aunque podían mantenerse dentro de ellas siempre y cuando los desagües estuvieran enterrados ${ }^{79}$, en los establecimientos para la obtención de almidón se debían limpiar las balsas cada dos días evitando así la «corrupción» del agua ${ }^{80}$. Todas estas medidas se fueron tomando en diferentes momentos del siglo y tras unos debates que, muchas veces, implicaron a varios actores con intereses encontrados. Al margen de

73. Alberola Romá, 7 (1989): 69-81, Rosser LimiñanA, (2003): 17-22.

74. AMA, Arm. 9, lib. 36, ff. 100-101.

75. AMA, Arm. 9, lib. 36, ff. 162v-165.

76. AMA, Arm. 9, lib. 2, ff. 60-60v y 62v-63.

77. Medio cuarto de legua, según la ordenanza, AMA, Arm. 9, lib. 47, ff. 240v y 247.

78. AMA, Arm. 9, lib. 42, f. 170.

79. AMA, Arm. 9, lib. 43, f. 200v.

80. AMA, Arm. 9, lib. 74, f. 157. 
estas políticas municipales, también encontramos ciertas intervenciones por parte del Estado central, como fue la prohibición de inhumar en los templos dispuesta por Carlos III que data de 1784, y que fue ratificada tres años más tarde por una Real Cédula ${ }^{81}$.

\section{Actuación ante la epidemia}

Una vez que ya había prendido el contagio de tercianas, la actuación del cabildo se movía en dos direcciones. Por un lado, debía recabar toda la información posible y, por otro, debía asegurar que se diera la asistencia sanitaria y la distribución de remedios entre los enfermos. En la mayoría de ocasiones, cuando se había estabilizado el brote, únicamente restaba dejar pasar el tiempo hasta que este estuviera sofocado, sanando la propia naturaleza a los pacientes. No obstante, en ocasiones en las que se consideró el brote más grave, se podían articular otras medidas como evitar los contextos que promovían aglomeraciones como las ferias, o la prohibición de los espectáculos públicos, tanto para evitar muchedumbres, como para avivar la contrición de los fieles e inspirar el favor divino para que cesara el contagio. De hecho, en última instancia, podía recurrirse al rezo de toda la comunidad, convocándose la celebración de rogativas por salud, como ocurrió en $1768^{82}$.

Habida cuenta de la constante presencia de las tercianas, este era un tema que no solía entrar en la agenda del cabildo, puesto que la enfermedad se podía controlar con los recursos asistenciales que existían. Sin embargo, cuando se hacía patente que el contagio había rebasado los límites considerados «normales» se ponía en marcha un protocolo de actuación no escrito, pero que en todos los casos se desarrolló del mismo modo. El primer paso consistía en realizar una averiguación para saber cuál era realmente la enfermedad que afectaba a la población. Para ello, se contó principalmente con los tres médicos que la ciudad tenía contratados para atender a los vecinos pobres $^{83}$. En ocasiones, también se solicitaba la opinión de las órdenes religiosas (franciscanos y capuchinos), el clero de las parroquias y, sobre todo, al prior del Hospital de San Juan de Dios.

81. SANTONJA CARDONA, 17 (1998): 33-44.

82. Perdiguero GiL, 22 (2002): 121-150.

83. Perdiguero Gil y Bernabeu Mestre, 11 (1995): 165-176. 
Además de conocer el diagnóstico, se imponía saber cuál era el origen de la dolencia. Durante todo el siglo XVIII, la respuesta apuntaba hacia los focos de insalubridad anteriormente señalados y, en rara ocasión, los expertos dictaminaron que la enfermedad procediese de fuera. Por supuesto, también se recabó información acerca del número de contagios, para lo que, nuevamente, fue fundamental la labor de los médicos asalariados. Las cifras recogidas, no obstante, eran habitualmente muy vagas, realizando únicamente estimaciones, algo usual, por otro lado, al tratarse de una época pre estadística. Una excepción a este último punto la encontramos en el contexto de 1786 cuando, por orden del Corregidor, sí se llevó a cabo una pesquisa que aportó cifras más precisas.

Una vez se tenía conocimiento de las circunstancias que envolvían al brote, se hacía necesario hacer llegar la ayuda a los afectados. Para ello, los tres médicos realizaban sus visitas en el ámbito doméstico, que era donde se vivía la enfermedad y, llegado el caso, la muerte. No obstante, los afectados también podían ser cuidados en el Hospital de San Juan de Dios, la Casa de Misericordia, o en los monasterios de franciscanos y capuchinos $^{84}$. Como es evidente, al margen de los sanitarios cuyo oficio estaba regulado por la administración (médicos, cirujanos, farmacéutico, matronas) y religiosos, también se podía recurrir a otras instancias asistenciales como sanadores no titulados (charlatanes, curanderos), o a los cuidados proporcionados dentro de las redes de solidaridad familiar o vecinal, dando forma, de ese modo, a la compleja realidad que rodea a la enfermedad.

La ayuda distribuida a los dolientes por el cabildo consistía en limosna, alimentos, nieve, agua fría y medicamentos. Teniendo en cuenta la condición pauperizable de la mayoría de la población, el acceso a esta ayuda era fundamental, puesto que la pérdida de unas jornadas de trabajo podía arrojar a toda una familia a vivir de la caridad. En el caso de la comida, en ese contexto de escasez, un aporte nutritivo extra solía ser una buena medida, toda vez que se consideraba que el puchero de gallina poseía propiedades curativas, formando parte esencial de la terapéutica del momento. La nieve y la limonada eran muy apreciadas en la época para hacer frente a las fiebres en

84. Había más órdenes religiosas, masculinas y femeninas, pero no hay constancia de que llevaran a cabo labores asistenciales. 
general, además, también se tomaban en contexto recreativos. Por su parte, las fuentes no mencionan qué medicamentos eran los dispensados y no se alude a la quina, remedio tradicional contra las calenturas, pero muy costoso de conseguir ${ }^{85}$. No obstante, en una institución particular como el Hospital Militar de la ciudad, el viajero Joseph Tonwnsend relataba el uso de la sangría como método para tratar las tercianas por los médicos, además del empleo de la quina ${ }^{86}$.

La atención a los enfermos distó mucho de satisfacer a todos los vecinos quienes, reiteradamente, hicieron llegar al cabildo protestas por la falta de asistencia que sufrían. Esta circunstancia se hacía aún más evidente en momentos epidémicos, cuando se multiplicaban las personas necesitadas de cuidados. Los ejemplos en este sentido son muy abundantes y por mencionar uno de ellos, encontramos una de estas quejas vecinales cuando, durante el contagio de 1766, murió un morador en el centro de la ciudad sin haber recibido la asistencia del médico encargado de esa zona, un hecho que solo le mereció la amonestación por parte de los regidores, puesto que no se solían tomar medidas más severas contra los facultativos ${ }^{87}$. Esta insuficiencia de los recursos se puede apreciar igualmente en el Hospital de San Juan de Dios, donde sus treinta camas no eran suficientes para atender a quienes necesitaban asistencia, quedando desbordado de inmediato cuando acontecía algún brote tercianario.

\section{Conclusiones}

Tal y como hemos venido desarrollando a lo largo del texto, las fiebres tercianas fueron una realidad presente y recurrente en la sociedad alicantina del siglo XVIII. Se trató de una enfermedad típica del medio, y también muy característica del Setecientos. Aunque no supuso un freno demográfico reseñable, ni tampoco despertó el pánico entre la población, sí fue un problema al que fue necesario hacer frente, llevando a cabo cierta labor de prevención y, llegado el caso, poniendo en marcha medidas de actuación por parte de los poderes municipales a fin de que la asistencia llegara a todos los vecinos.

85. Riera PALMERO, 52 (1994): 6-28.

86. TONWNSEND, 1792: 168-224.

87. AMA, Arm. 9, lib. 56, ff. 227-227v

Revista de Historia Moderna, n. ${ }^{\circ} 35$ (2017) (pp. 377-409) | ISSN-e: 1989-9823 | ISSN: 0212-5862 
La labor preventiva consistió, por un lado, en eliminar las porciones de aguas estancadas que se formaban en las inmediaciones de la ciudad y, por otro, en tratar de regular, prohibiendo o alejando del núcleo urbano, las actividades que podían suponer, desde el enfoque científico de la época, un peligro para la salud. La actuación que se llevó a cabo cuando el brote palúdico se había extendido por la ciudad, consistió en recabar información sobre el número de enfermos, qué tipo de enfermedad padecían y, si era posible, averiguar el origen de la misma para, intentar actuar sobre este.

La segunda parte de la acción política aplicada consistió en asegurar la atención médica y distribuir los socorros oportunos (limosna, comida, nieve y medicinas). Tanto para la labor preventiva como para la curativa, el trabajo de los médicos fue fundamental, puesto que actuaban de correa de transmisión entre el consistorio y la población. Además, en contadas ocasiones, se tomó la determinación de suspender diversiones públicas y convocar rogativas. Teniendo en cuenta la naturaleza de las tercianas, siendo una enfermedad hasta cierto punto previsible y que no causaba estragos, una vez se había asegurado la asistencia al vecindario únicamente restaba dejar pasar el tiempo hasta que, con el fresco del otoño, acabase por remitir.

En relación al vínculo existente entre el tiempo atmosférico y la aparición de las tercianas durante el verano y el principio del otoño, hemos podido observar que los excesos hidrometeorológicos que precedían al estío, podían llevar aparejados un repunte de los casos de malaria. Los brotes epidémicos aparecieron en años en los que no fue necesario convocar rogativas pro pluvia y que, por lo tanto, no se experimentaba una necesidad acuciante de lluvia. Dos excepciones hemos encontrado en 1753 y 1786, aunque en ambos casos también las precipitaciones durante los meses anteriores fueron considerables.

Los episodios típicos de lluvias de alta intensidad horaria durante los equinoccios, añadidos a las condiciones geográficas del medio alicantino, propiciaban la aparición de lagunas que, durante la estación cálida, se convertían en el ambiente ideal para la proliferación del mosquito transmisor de la enfermedad. En el lado opuesto, en los periodos de tiempo en los que se experimentó fuerte escasez hídrica, no se registraron brotes palúdicos de consideración. Como hemos insistido a lo largo del trabajo, el objetivo no ha sido establecer una correlación causal inmediata, sino señalar otro aspecto a tener en cuenta a la hora de conocer las sociedades pasadas, donde la aparición de 
las lluvias, si bien era fundamental para la economía agrícola, también podía provocar destrozos y derivar en la aparición de la malaria.

Por último, cabe destacar que, a través de los casos documentados, por el momento no parece posible establecer una relación entre la mayor variabilidad climática que se experimentó en las décadas finales de siglo y una mayor incidencia del paludismo. Es cierto que, de los nueve casos registrados durante el siglo XVIII, seis de ellos se produjeron en las últimas cuatro décadas, coincidiendo con la anomalía Maldá. No obstante, teniendo en cuenta el crecimiento poblacional desde el principio de la centuria y, por tanto, del reservorio de la enfermedad, obliga a tomar con cautela este aumento de los casos. Además, la ciudad creció hacia lagunas y almarjales, de modo que también se ampliaron las posibilidades de exposición a la picadura y, por tanto, al contagio.

\section{Bibliografía}

Alberola RomÁ, Armando, «Una enfermedad de carácter endémico en el Alicante del siglo XVIII: las fiebres tercianas», Revista de Historia Moderna. Anales de la Universidad de Alicante, 5 (1985): 127-140. http://dx.doi.org/10.14198/ RHM1985.5.03

Alberola RomÁ, Armando, «La bonificación de enclaves insalubres en el País Valenciano durante la Edad Moderna. El ejemplo de la laguna de la Albufereta (Alicante)», Investigaciones Geográficas, 7 (1989): 69-81. http://dx.doi. org/10.14198/INGEO1989.07.01

Alberola RomÁ, Armando, El pantano de Tibi y el sistema de riegos en la Huerta de Alicante, Alicante, Instituto de Cultura «Juan Gil-Albert»-Fundación CAM (2. ${ }^{a}$ ed. corregida y aumentada), 1994.

Alberola RomÁ, Armando, Catástrofe, economía y acción política en la Valencia del siglo XVIII, Valencia, Institució Alfons el Magnànim, 1999.

Alberola RomÁ, Armando, «De la percepción popular a la reflexión erudita. La transmisión de la cultura de la catástrofe en la España del siglo XVIII», en Serge Salaün y Françoise Étienvre (eds.), La réception des cultures de masse et des cultures populaires en Espagne: XVIIIe-XXe siècles, París, Université de Paris III, 2009: 39-67. Disponible en http://crec-paris3.fr/wp-content/uploads/2011/07/ actes-02-Alberola.pdf [consultado el 26 de mayo de 2016] 
Alberola RomÁ, Armando, Quan la pluja no sap ploure. Sequeres i riuades al País Valencià en l'edat moderna, València, Publicacions de la Universitat de València, 2010.

Alberola RomÁ, Armando, «Un 'mal año' en la España del siglo XVIII: clima, desastre y crisis en 1783», en Xavier Huertz de Lemps y Jean-Philippe Luis (eds.), Sortir du labyrinthe. Études d'histoire contemporaine de l'Espagne. Hommage à Gérard Chastagnaret, Madrid, Casa de Velázquez (131), 2012: 325-346.

Alberola Romá, Armando, Los cambios climáticos. La pequeña edad del hielo en España Madrid, Cátedra, 2014.

Alberola RomÁ, Armando, «Tiempo, clima y enfermedad en la prensa española de la segunda mitad del siglo XVIII. Diarios meteorológicos y crónicas de desastres en el Memorial Literario», El Argonauta español, 12 (2015). http:// dx.doi.org/10.4000/argonauta.2142

Alberola RomÁ, Armando, "Clima, catástrofe y crisis en la España de la Edad Moderna. Reflexiones y notas para su estudio», en Fernando J. Vera, Jorge Olcina Cantos y María Hernández (coords.), Paisaje, cultura territorial y vivencia de la Geografía, Alicante, Universidad de Alicante, 2016: 739-759. Disponibel en: http://hdl.handle.net/10045/58781 [consultado el 26 de mayo de 2016]

Alberola RomÁ, Armando y Bernabé GIL, David, «Tercianas y calenturas en tierras meridionales valencianas: una aproximación a la realidad médica y social del siglo XVIII», Revista de Historia Moderna. Anales de la Universidad de Alicante, 17 (1999): 95-112. http://dx.doi.org/10.14198/RHM1998-1999.17.06

Alberola Romá, Armando, Bueno Vergara, Eduardo y García Torres, Adrián, «Sequía y rogativas en tierras meridionales valencianas durante el siglo XVIII», en Luis Alberto Arrioja Díaz Viruell y Armando Alberola Romá (eds.), Clima, desastres y convulsiones sociales en España e Hispanoamérica, siglos XVI-XX, Zamora (México)/Alicante, El Colegio de Michoacán/Universidad de Alicante, 2016: 123-155.

Alberola Romá, Armando y Pradells Nadal, Jesús, «Sequía, inundaciones, fiebres y plagas en tierras aragonesas y catalanas (1780-1790)», en David Bernabé Gil y Armando Alberola Romá (coords.), Magistro et amico. Diez estudios en Homenaje al profesor Enrique Giménez López, Alicante, Publicaciones de la Universidad de Alicante, 2012: 65-93. 
Arcos GonZÁlez, Pedro y Escolano Escobar, Cristian, «Enfermedades de transmisión vectorial potencialmente emergentes en la cuenca mediterránea y su posible relación con el cambio climático», Emergencias, 23/5 (2011): 386393. Disponible en: http://emergencias.portalsemes.org/numeros-anteriores/ volumen-23/numero-5/ [consultado el 26 de mayo de 2016]

Arrioja díaz Viruell, Luis Alberto y Alberola Romá, Armando (eds.), Clima, desastres y convulsiones sociales en España e Hispanoamérica, siglos XVIXX, Zamora (México)/ Alicante, El Colegio de Michoacán/Universidad de Alicante, 2016.

ARRIZABALAGA, Jon, «La identificación de las causas de muerte en la Europa pre-industrial: algunas consideraciones historiográficas», Revista de demografía histórica, 11/3 (1993): 23-47. Disponible en: http://hdl.handle.net/10261/33473 [consultado el 26 de mayo de 2016]

ASED LatorRe, Antonio, Memoria instructiva de los medios de precaver las malas resultas de un Temporal excesivamente humedo, como el que se ha observado desde principios de Setiembre de 1783, hasta últimos de Abril de 1784 leida en Junta general de la Real Sociedad Aragonesa de Amigos del pais el día 7 de Mayo, Zaragoza, Imprenta de Blas Miedes, 1784. Disponible en: http://bdh-rd.bne. es/viewer.vm?id=0000106605\&page $=1$ [consultado el 26 de mayo de 2016] BARRIENDOS VAllVÉ, Mariano, «El clima histórico de Catalunya (siglos XIV-XIX). Fuentes, métodos y primeros resultados», Revista de Geografía, 30-31 (1996): 69-96. Disponible en: http://hdl.handle.net/10459.1/43700 [consultado el 26 de mayo de 2016]

Barriendos Vallvé, Mariano y Llasat, M. Carmen, «El caso de la anomalía «Maldá» en la cuenca mediterránea occidental (1760-1800). Un ejemplo de fuerte variabilidad climática», en Armando Alberola Romá y Jorge Olcina Cantos (eds.), Desastre natural, vida cotidiana y religiosidad popular en la España moderna y contemporánea, Alicante, Publicaciones de la Universidad de Alicante, 2009: 253-286.

BRAUDEL, Fernand, El Mediterráneo y el mundo mediterráneo en la época de Felipe II, México, Fondo de Cultura Económica, 2010.

Bueno Marí, Rubén y JimÉnEz PEYdRó, Ricardo, «Crónicas de arroz, mosquitos y paludismo en España: el caso de la provincia de Valencia (S. XVIII-XX)», Hispania: Revista española de Historia, 70/236 (2010): 687-708. http://dx.doi. org/10.3989/hispania.2010.v70.i236.329 
Bueno Marí, Rubén y JimÉnez Peydró, Ricardo, « ¿Pueden la malaria y el dengue reaparecer en España?», Gaceta Sanitaria, 24/4 (2010): 347-353. Disponible en: Disponible en: http://scielo.isciii.es/scielo.php?script=sci_arttext\&pi$\mathrm{d}=$ S0213-91112010000400014\&lng=es\&nrm=iso [consultado el 26 de mayo de 2016]

BUENO VergarA, Eduardo, «Un indicador climático para el Alicante del siglo XVIII. Los manifiestos del vino», en Armando Alberola Romá (coord.), Clima, naturaleza y desastre. España e Hispanoamérica durante la Edad Moderna, Valencia, Universitat de València, 2013: 55-79. Disponible en: http://www.academia. edu/29193903/Un_indicador_clim\%C3\%Altico_para_el_Alicante_del_siglo_ XVIII._Los_manifiestos_del_vino [consultado el 26 de mayo de 2016]

Bueno Vergara, Eduardo, Clima y medicina en el Alicante del siglo XVIII. Amenazas medioambientales, vulnerabilidad social y estrategias de resistencia, Universidad de Alicante, 2014. Disponible en: http://hdl.handle.net/10045/44521 [consultado el 26 de mayo de 2016]

Callahan, William, «Caridad, sociedad y economía en el siglo XVIII», Moneda y Crédito, 146 (1978): 65-71.

CAPEL SÁEZ, Horacio, «Medicina y clima en la España del siglo XVIII», Revista de Geografía, 32-33 (1998): 79-105. Disponible en: http://hdl.handle. net/10459.1/43705 [consultado el 26 de mayo de 2016]

Carasa Soto, Pedro, «Cambios en la tipología del pauperismo en la crisis del Antiguo Régimen», Investigaciones Históricas: Época Moderna y Contemporánea, 7 (1987a): 131-150. Disponible en: http://uvadoc.uva.es/handle/10324/21283 [consultado el 26 de mayo de 2016]

CARASA Soto, Pedro, Pauperismo y revolución burguesa (Burgos, 1750-1900), Valladolid, Universidad de Valladolid, 1987b.

CARRERAs PANCHÓn, Antonio, Miasmas y retrovirus. Cuatro capítulos de la historia de las enfermedades transmisibles, Barcelona, Fundación Uriach, 1991.

CiBat, Antonio, Memoria sobre el problema ¿Por qué motivos o causas las tercianas se han hecho tan comunes y graves en nuestra España? ¿Con qué medios podrían precaverse y destruirse?, Madrid, Imprenta Real, 1806. Disponible en: http://bipadi.ub.edu/cdm/ref/collection/epidemies/id/1407 [consultado el 26 de mayo de 2016]

Cipolla, Carlo María, Contra un enemigo mortal e invisible (apuntes del libro), Barcelona, Crítica, 1993. 
CONTRERAS Mas, Antonio, «Epidemiología rural mallorquina a fines del siglo XVIII», Trabajos de Geografía, 37 (1980): 83-90. Disponible en: http://www. raco.cat/index.php/TreballsGeografia/article/view/104008 [consultado el 26 de mayo de 2016]

CORBIN, Alain, El perfume o el miasma. El olfato y lo imaginario social. Siglos XVIII y XIX, México, Fondo de Cultura Económica, 1987.

CuAdrat Prats, José María, «Reconstrucción de los episodios de sequía en el nordeste de España a partir de las ceremonias de rogativas», Nimbus: Revista de Climatología, Meteorología y Paisaje, 29-30 (2012): 177-187. Disponible en: http://hdl.handle.net/10835/2979[consultado el 26 de mayo de 2016]

DíAz PINTAdo, Juan, «Epidemias de paludismo en la Mancha del XVIII», Cuadernos de estudios manchegos, 21 (1991): 213-247. Disponible en: https:// previa.uclm.es/ceclm/b_virtual/revistas/CEM/cecm2_21.htm [consultado el 26 de mayo de 2016]

FERNÁNDEZ CORTIZO, Camilo, « ¿En Galicia, el hambre entra nadando? Rogativas, clima y crisis de subsistencia en la Galicia litoral sudoccidental en los siglos XVI-XVIII», Semata, Ciencias Sociais e Humanidades, 17 (2005): 259-298. Disponible en: http://hdl.handle.net/10347/4459 [consultado el 26 de mayo de 2016]

FRANCO RUBIO, Gloria, «La fragilidad de la vida cotidiana en la España moderna», en Armando Alberola Romá y Jorge Olcina Cantos (eds.), Desastre natural, vida cotidiana y religiosidad popular en la España moderna y contemporánea, Alicante, Universidad de Alicante, 2009: 209-251.

GARCíA RuIPÉREZ, Mariano y SÁNCHEZ GONZÁLEZ, Ramón, «Crisis demográficas y crisis agrarias: paludismo y agricultura en España a finales del siglo XVIII», Asclepio, 43/1 (1991): 267-299.

GARNIER, Emmanuel, «Les brouillards du Laki en 1783. Volcanisme et crise sanitaire en Europe», Bulletin de l'Academie nationale de medecine, 195/4-5 (2011): 1043-55.

GIMÉNEZ FONT, Pablo, «La epidemia de malaria de 1783-1786: notas sobre la influencia de anomalías climáticas y cambios de usos del suelo en la salud humana», Investigaciones Geográficas, 46 (2008): 141-157. http://dx.doi. org/10.14198/INGEO2008.46.08

GIMÉNEZ LÓPEZ, Enrique, Alicante en el siglo XVIII. Economía de una ciudad portuaria en el Antiguo Régimen, Valencia, Institución Alfonso el Magnánimo, 1981. 
GitheKo, Andrew K., LindSAY, Steve W, CONFALONIERI, Ulisses E y PATZ, Jonathan A, «Climate change and vector-borne diseases: a regional analysis», Bulletin of the World Health Organization, 78/9 (2000): 1136-1147. Disponible en: http:// www.who.int/iris/handle/10665/57713 [consultado el 26 de mayo de 2016]

GUERRAND, Roger-Henri, Las letrinas. Historia de la higiene urbana, Valencia, Institució Alfons el Magnànim, 1991.

LARREA KILLINGER, Cristina, La cultura de los olores. Una aproximación a la antropología de los sentidos, Quito, Ediciones Abya-Yala, 1997. Disponible en: https:// repository.unm.edu/handle/1928/10549 [consultado el 26 de mayo de 2016] LARREA Killinger, Cristina, «La colonización olfativa de la medicina. Cuerpos y espacios urbanos», Calle 14: Revista de investigación en el campo del arte, 4/5 (2010): 24-43. Disponible en: http://www.redalyc.org/articulo. oa? id=279021514003 [consultado el 26 de mayo de 2016]

LARRIBA, Elisabel, «De l'usage de la gravure dans le Memorial literario (17841808)», El Argonauta español, 5 (2008). http://dx.doi.org/10.4000/ argonauta.954

LARRIBA, Elisabel, «La última salida al ruedo del Memorial literario (10 de octubre-20 de noviembre de 1808)», Cuadernos de Ilustración y Romanticismo. Revista digital del Grupo de Estudios del Siglo XVIII, 16 (2010): 1-88. Disponible en: http://revistas.uca.es/index.php/cir/article/view/183 [consultado el 26 de mayo de 2016]

LÓPEZ VÉlEZ, Rogelio y MOLINA MORENO, Ricardo, «Cambio climático en España y riesgo de enfermedades infecciosas y parasitarias transmitidas por artrópodos y roedores», Revista Española de Salud Pública, 79/2 (2005): 177190. Disponible en: http://scielo.isciii.es/scielo.php?script=sci_arttext\&pi$\mathrm{d}=$ S1135-57272005000200006 [consultado el 26 de mayo de 2016]

MARTín VIDE, Javier y BARRIENDOS VALLVÉ, Mariano, «The use of rogation ceremony records in climatic reconstruction: a case study from Catalonia (Spain)», Climatic Change, 30/2 (1995): 201-221.

MASDEVALL, Joseph, Relación de las epidemias de calentura pútridas y malignas que en estos últimos años se han padecido en el Principado de Cataluña, Madrid, Imprenta Real, 1797. Disponible en: http://www.cervantesvirtual.com/obra/ relacion-de-las-epidemias-de-calenturas-putridas-y-malignas-que-en-estos-ultimos-anos-se-han-padecido-en-el-principado-de-cataluna-y-principalmente-de-la-que-se-descubrio-el-ano-pasado-de-1783-en-la-ciudad-de- 
lerida-llano-de-urgel-y-otros-muchos-corregimi [consultado el 26 de mayo de 2016]

MATEU TORTOSA, Enric, Arroz y paludismo: riqueza y conflictos en la sociedad valenciana del siglo XVIII, Valencia, Edicions Alfons el Magnànim, 1987.

MAZA ZORRILla, Helena, Valladolid: sus pobres y la respuesta institucional (17501900), Valladolid, Universidad de Valladolid, 1987.

McMichael, Anthony J, WoOdruff, Rosalie E y HALES, Simon, «Climate change and human health: present and future risks», The Lancet, 367/9513 (2006): 859-869. https://doi.org/10.1016/S0140-6736(06)68079-3 [consultado el 26 de mayo de 2016]

Olmos TAMARIT, Vicent, «Arrós, prosperitat i malaltia, número monográfico de la revista Afers», Afers: fulls de recerca i pensament, 16 (2001).

Perdiguero GiL, Enrique, «Con medios divinos y humanos: la lucha contra la enfermedad y la muerte en Alicante en el siglo XVIII», Dynamis, 22 (2002): 121-150. Disponible en: http://www.raco.cat/index.php/Dynamis/article/ view/92756 [consultado el 26 de mayo de 2016]

Perdiguero Gil, Enrique y Bernabeu Mestre, Josep, «La asistencia médica pública en el Alicante del siglo XVIII: los médicos de la ciudad», Canelobre, 11 (1995): 165-176.

PÉREZ MedinA, Tomás V., «Arròs, paludisme i població a la comarca de l'Horta. L'epidemia de 1784», Afers: fulls de recerca i pensament, 6/11-12 (1991): 137-150.

PÉREZ MOREDA, Vicente, Las crisis de mortalidad en la España interior (siglos XVIXIX), Madrid, Siglo XXI, 1980.

PÉREZ MOREDA, Vicente, «El paludismo en España a fines del siglo XVIII: La epidemia de 1786», Asclepio, 34 (1982): 295-316.

PÉREZ MoredA, Vicente, «Notas para una Historia del paludismo en España», Jano, 30/728 (1986): 51-64.

Peset Reig, José Luis y Peset Reig, Mariano, «Cultivos de arroz y paludismo en la Valencia del siglo XVIII», Hispania: Revista española de Historia, 121 (1972): 277-375.

Peset Reig, José Luis y Peset ReIG, Mariano, Muerte en España (política y sociedad entre la peste y el cólera), Madrid, Seminarios y Ediciones, 1972.

Peset Reig, José Luis y Peset Reig, Mariano, «Epidemias y sociedad en la España del Antiguo Régimen», Estudios de Historia Social, 4 (1978): 7-28. 
ReITER, Paul, «Climate Change and Mosquito-Borne Disease», Environmental Health Perspectives, 109/Supplement 1 (2001): 141-161. Disponible en: https:// www.ncbi.nlm.nih.gov/pmc/articles/PMC1240549/pdf/ehp109s-000141.pdf [consultado el 26 de mayo de 2016]

Riera PALMERO, Juan, «Quina y malaria en la España del siglo XVIII», Medicina e Historia, 52 (1994): 6-28.

RODRíGUEZ OCAÑA, Esteban, «El resguardo de la salud. Organización sanitaria española en el siglo XVIII», Dynamis, 7-8 (1988): 145-170. Disponible en: http://hdl.handle.net/10481/19833 [consultado el 26 de mayo de 2016]

Rodríguez Ocaña, Esteban y Martínez Navarro, Ferrán, Salud pública en España. De la Edad Media al siglo XXI, Sevilla, Escuela andaluza de Salud Pública, 2008. Disponible en: http://www.easp.es/project/salud-publica-enespana-de-la-edad-media-al-siglo-xxi-serie-nueva-salud-publica [consultado el 26 de mayo de 2016]

RogERS, David J y RANDOlPH, Sarah E, «The Global Spread of Malaria in a Future, Warmer World», Science, 289/5485 (2014): 1763-1766. Disponible en: http:// science.sciencemag.org/content/289/5485/1763.full [consultado el 26 de mayo de 2016]

Romero Martín, Lidia y MÁyer SuÁrez, Pablo, «Episodios de sequía en Gran Canaria en el siglo XVII: análisis de las rogativas como método de reconstrucción climática», en José Antonio Guijarro Pastor, Miquel Grimalt Gelabert, Mercedes Laita Ruiz de Asúa y Sergio Alonso Oroza (eds.), El agua y el clima, Mallorca, Asociación Española de Climatología, 2002: 533-542. Disponible en: http://hdl.handle.net/10553/863

Rosser LimiÑAna, Pablo, «El medio físico de La Albufereta y su evolución», LQNT. Monográfico 2, (2003): 17-22. Disponible en: http://www.alicante.es/ es/publicaciones/lqnt-2-monografico-2-cerro-balsas-y-chinchorro [consultado el 26 de mayo de 2016]

SÁEz GÓMEZ, José Miguel y MARSET CAMPOS, Pedro, «Teoría académica y práctica ciudadana en el paludismo. Las causas de las enfermedades endémicas en Murcia durante el siglo XVIII desde la perspectiva de la administración local», Asclepio, 52/1 (2000): 167-184. http://dx.doi.org/10.3989/asclepio.2000.v52. il.194

SANTONJA CARDONA, José Luis, «La construcción de cementerios extramuros: un aspecto de la lucha contra la mortalidad en el Antiguo Régimen», Revista de Historia Moderna. Anales de la Universidad de Alicante, 17 (1998): 33-44. 
Disponible en: http://hdl.handle.net/10045/4765 [consultado el 26 de mayo de 2016]

SChmidt, Anja, Ostro, Bart, CARSLAW, Kinneth, Wilson, Marjorie, THORDARSON, Thorvaldur, MANN, Graham y SimmONS, Adrian, «Excess mortality in Europe following a future Laki-style Icelandic eruption», Proceedings of the National Academy of Sciences of the United States of America Proc Natl Acad Sci U S A, 108/38 (2011): 15710-5. http://dx.doi.org/10.1073/pnas.1108569108 Sobrevía Clavera, Andrés, «El cultivo del arroz de secano en Cataluña (17781839). Una propuesta agronómica al problema del paludismo», Asclepio, 55/2 (2004): 169-196. http://dx.doi.org/10.3989/asclepio.2004.v56.i2.43

SOUBEYROUX, Jacques, «Pauperismo y relaciones sociales en el Madrid del siglo XVIII (I)», Estudios de Historia Social, 12-13 (1980): 7-227.

SOUBEYROUX, Jacques, «El encuentro del pobre y la sociedad. Asistencia y represión en el Madrid del siglo XVIII», Estudios de Historia Social, 20-21 (1982): 7-225.

THORDASOn, Thorvaldur y SELF, Stephen, «Atmospheric and environmental effects of the 1783-1784 Laki eruption: A review and ressessment», Journal of Geophysical research, 108/D1 (2003): 1-29. http://dx.doi. org/10.1029/2001JD002042

TONWNSEND, Joseph, A journey through Spain in the years 1786 and 1787, Londres, C. Dilly, in the Poultry, 1792. Disponible en: http://bivaldi.gva.es/es/consulta/ registro.cmd?id=3388 [consultado el 26 de mayo de 2016]

URTEAGA, Luis, «Miseria, miasmas y microbios. Las topografías médicas y el estudio del medio ambiente en el siglo XIX», Cuadernos Críticos de Geografía Humana, 29 (1980). Disponible en: http://www.ub.edu/geocrit/geo29.htm [consultado el 26 de mayo de 2016]

URTEAGA, Luis, «Higienismo y ambientalismo en la medicina decimonónica», Dynamis, 5-6 (1985): 417-425. Disponible en: http://www.raco.cat/index.php/ Dynamis/article/view/121798/170265 [consultado el 26 de mayo de 2016] URZAINQUI MiQUELEIZ, Inmaculada, «Los redactores de «Memorial Literario» (1784-1808)», Estudios de Historia Social, $52-53$ (1990): 501-516. Disponible en: http://hdl.handle.net/10651/25113 [consultado el 26 de mayo de 2016] Witham, Claire y OpPenHeIMER, Clive, «Mortality in England during the 1783-4 Laki Craters eruption», Bulletin of Volcanology, 67/1 (2004): 15-26. http:// dx.doi.org/10.1007/s00445-004-0357-7 
ZAMOrA PASTOR, Ruth, El final de la Pequeña Edad del Hielo en Alicante, Alicante, Universidad de Alicante, 2002.

ZHOU, Guofa, Minakawa, Noboru, Githeko, Andrew K. y Yan, Guiyun, «Association between climate variability and malaria epidemics in the East African Highlands», Proceedings of the National Academy of Sciences of the United States of America, 101/8 (2004): 2375-2380. http://dx.doi.org/10.1073/ pnas.0308714100 